\title{
An assessment of reproductive health services in selected health facilities, Anambra State, Nigeria
}

\author{
Chigozie Ozoemena Ifeadike*, Nkiru Nwamaka Ezeama, Godswill Amechi Nnaji, Obiageli Fidelia Emelumadu, Uchenna Ugwoke and \\ Cosmas Chiedozie Ofoegbu
}

${ }^{*}$ Correspondence: gozifeadike@yahoo.com

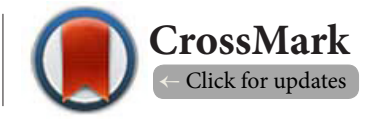

Department of Community Medicine/ Primary Health Care, Nnamdi Azikiwe University Teaching Hospital, Awka, Anambra state, Nigeria.

\begin{abstract}
The national figure for skilled attendance at delivery in Nigeria is 38.1 percent, with some observed regional difference. In Anambra State for instance, 87.6 percent of deliveries are taken by skilled providers. However, the efficiency and effectiveness of skilled providers can be hampered by a lack of essential reproductive health drugs, commodities, supplies and equipment.

Aim: Of this study is to assess reproductive health care services in Anambra State, Nigeria.

Methodology: This is a descriptive study carried out in Anambra state of Nigeria in 2010. A stratified multi stage sampling method was used to select a total of 30 health facilities from both the public and private health facilities in Anambra state of Nigeria. A tertiary health facility in Anambra state was purposively selected and data was analysed using SPSS.

Results: A majority (86.7\%) of the facilities provided 24 hours services. All, except two of the facilities surveyed were open for services seven days of the week. Maternal health services such as antenatal care, delivery, and postnatal care were available in most of the health facilities studied (93\% to 100\%). The comprehensive emergency obstetrics care (26.7\%) was the most common type of emergency obstetric care. Nurses constituted the most frequent cadre (57.4\%) among the various categories of skilled health attendants, followed by medical non specialist doctors (31.1\%). Seven facilities used partograph to monitor labour, while 11 health facilities provided adolescent reproductive health care services. HIV/AIDS counselling and STI services (ranging from 90\% to 96\%) were available in most of the health facilities studied. A majority of deliveries were conducted in the National teaching hospital (36.8\%) followed by mission hospital (31.1\%), while Mission hospitals reported the highest rate (13.2\%) of Caesarean section performed in the health facilities. Obstetric haemorrhage constituted the commonest obstetric complication (88.7\%) followed by prolonged/ obstructed labour $(6.8 \%)$ found in the health facilities studied.

Conclusion: The reproductive health services in Anambra state with specific reference to services coverage was found to be near adequate, although there is room for improvement.

Keywords: Assessment of reproductive health services, emergency obstetric care services, basic emergency obstetrics care services, Anambra State, Nigeria
\end{abstract}

\section{Introduction}

There have been global paradigm shifts in the concept of Reproductive Health care over the years. Since Alma Ata and the advent of primary health care in 1978, the concept of reproductive health has evolved from an earlier global policy focuson fertility control and family planning prior to the 1990s to a wider scope embracing broader health and social contexts at the International Conference on Population and Development (ICPD) in 1994, a scope which continues to expand today [1]. Since ICPD 1994, several key components have been added to the concept of reproductive health which include: family planning; maternal and newborn health care; prevention, diagnosis and treatment of sexually transmitted infections, including HIV; adolescent sexual and reproductive health; cancer screening; 
Ifeadike et al. Research Journal of Women's Health 2016,

and infertility counselling. Other areas include post-abortion care, the elimination of gender-based violence, harmful practices, coercion or abuse and gender inequalities [1].

Globally, reproductive health problems contribute significantly to the burden of disease and sub-Saharan Africa ranks highest among all World Health Organisation (WHO) regionsin total disability-adjusted life years lost due to reproductive ill health as a percentage of total DALYs lost among 15-44 year olds, $39.7 \%$ of DALYs among females and $8.5 \%$ among males [2]. Maternal and perinatal conditions, HIV/AIDS, STIs and cancers dominate this burden [3]. The 2013 Nigeria Demographic and Health Survey (NDHS) reportestimatesthe maternal mortality ratio at 576 maternal deaths per 100,000 live births [4]. Nigeria accounts for 10 percent of global maternal mortality losing about 52,900 women annually to death from pregnancyrelated complications $[5,6]$. The leading causes of maternal death in the country are haemorrhage, infections, unsafe abortions, eclampsia and obstructed labour although these conditions are preventable and treatable through access to adequate health-care services including safe and effective family planning methods and emergency obstetric care [7-10].

Lifesaving emergency obstetric care is core to reducing maternal and neonatal morbidity and mortality since many of the obstetric complications cause death within a critical time period [11]. Emergency obstetric care procedures are grouped under two categories, basic or comprehensive emergency obstetric care (EmOC). Basic EmOC comprises the ability of a health facility to provide the following services (signal functions): administration of parenteral antibiotics, parenteral oxytocics, parenteral anticonvulsants, manual removal of retained placenta, removal of retained products of conception, and assisted vaginal delivery either vacuum extraction or forceps deliveryand basic neonatal resuscitation. On the other hand, signal functions for comprehensive EmOCare the ability to provide blood transfusion and perform caesarean sectionin addition to basic EmOC [12]. Clear guidelines have been laid down for what constitutes minimum coverage for EmOC;for every 500,000 people, there should be at least five facilities providing emergency obstetric care with at least one of them providing comprehensive EmOC [12].

The partograph is a low-cost graphical tool that can be used in developing countries for monitoring labour where cardiotocographs are not available [17].

The importance of skilled health care providers to reproductive health care cannot be overemphasized. The national figure for skilled attendance at delivery in Nigeria is 38.1 percent [4]. There are however regional differences; in Anambra State for instance, 87.6 percent of deliveries are taken by a skilled provider [4]. The efficiency and effectiveness of skilled providers can however be hampered by a lack of essential reproductive health drugs, commodities, supplies and equipment.

The ICPD called for the integration of sexual and reproductive health into primary health care and since then, there has been a growing recognition of the need of an overall strengthen- ing of health systemsand achievement of universal access to reproductive health. Universal access to reproductive health requires a functioning health system that includes health facilities, trained personnel, a steady supply of relevant commodities and interventions [1]. This paper assesses reproductive health care services in Anambra State, Nigeria with specific reference to service coverage, maternal health, emergency obstetric care, HIV and STI management, treatment of non-communicable reproductive tract conditions, staffing and skilled birth attendance, supplies, equipment and infrastructure as well as obstetric records.

\section{Methodology \\ Study area}

The study was carried out in Anambra State, South Eastern Nigeria. The state consists of 21 local government areas (LGAs), 235 districts, 330 wards and 177 communities, with the administrative capital at Awka. The population of Anambra State is approximately 4.2 million people, about $3 \%$ of the Nigerian population according to the 2006 National Population Census figures [13]. The male:female sex ratio is 1.02: 1 (50.5\% and $49.5 \%$ of the population respectively) [14] and approximately $27.2 \%$ are women in reproductive age group (15-49 years). The peopleare predominantly Christians, traders, farmers and civil servants. According to the 2011 Nigeria Multiple Indicator Cluster Survey report, $62 \%$ of the Anambra population reside in urban areas while $64.3 \%$ and $78.3 \%$ of households have access to improved sources of drinking water and sanitary facilities, respectively [15].

Various categories of health care facilities provide health services to the population. Some of these belong to government, mission (faith based) organisations and private individuals. These include Nnamdi Azikiwe University Teaching Hospital (NAUTH), a Federal government-owned tertiary hospital, Anambra State University Teaching Hospital, a state-owned tertiary health facility and 32 secondary health facilities dispersed widely in the State. There are also 382 primary health care centres, 14 mission hospitals, 600 private hospitals, 186 maternity homes, 126 registered pharmaceutical premises, 10 health training institutions and 1,500 licensed patent medicine shops [16].

\section{Study design}

This paper was extracted from a descriptive study of maternal, newborn and child health care in Anambra State, Nigeria conducted on behalf of the Nigeria Federal Ministry of Health $(\mathrm{FMOH})$ in 2010. This paper reports the details of a health facility survey which was one of the three components of the FMOH project. The other two were a desk review of official documents relevant to maternal health in Anambra State and key informant interviews of selected officials in the Anambra State Ministry of Health.

\section{Study population and sampling technique}

The study population comprised government-owned and 
mission-owned health care facilities in Anambra. All government-owned and mission-owned health care facilities providing antenatal, delivery care and other maternal health services were eligible for inclusion in the study, while privately-owned health care facilities and government-ownedor mission-owned health care facilities that do not render maternal health services were excluded.

The selection of health facilities for assessment employed a multistage sampling technique in such a manner as to provide adequate spread in terms of geographical area (senatorial zonesand urban-rural settings) and categories and levels of health care facility (tertiary, secondary, primary and mission). Stratified sampling was used to select local government areas from the three senatorial zones in Anambra State namely Ekwusigo (rural), Nnewi North (urban), and Ihiala (mixed) LGAs from Anambra South senatorial zone; Anambra East (rural) and Onitsha South (urban) LGAs from Anambra North senatorial zone; and Idemili north (mixed), Awka South (mixed) and Njikoka (mixed) LGAs from Anambra Central senatorial zone. Lists of eligible health care facilities for each LGA served as sampling frames and health facilities were selected by simple random sampling. The LGAs designated as "mixed" were made up of both rural and urban areas therefore health facilities were selected from both areas in each mixed LGA by simple random sampling following stratification by geographical setting. One of the two government-owned tertiary health care facilities in the State, Nnamdi Azikiwe University Teaching Hospital Nnewi was purposively included in the survey. A total of 30 health facilities were included in the survey.

\section{Results}

Thirty health care facilities were surveyed out of which 22 were located in rural areas and eight were in urban areas. There were 11 hospitals including a federal government-owned teaching hospital which provided tertiary health care, five government general hospitals that provided secondary care and five mission/faith-based hospitals. In addition there were 19 government primary health care centres (Table 1).

\section{Service operation periods \& shift duties}

All except two of the facilities surveyed were open seven days of the week. These two facilities operated five days of the week except Saturdays and Sundays (Table 2) Overall, twenty-six (86.7\%) of the facilities surveyed provided 24-hour services. These were the federal government-owned tertiary facility, four secondary health facilities, 16 primary health care facilities and all five mission health facilities.

\section{Maternal health services}

Table 3 shows the availability of maternal health care services performed by the 30 health facilities. Twenty-nine health facilities provided antenatal care; all the health facilities provided delivery care while 28 provided postnatal care. Only 16 provided post-abortion care (out of which only nine were primary
Table 1. Distribution of $\mathbf{3 0}$ surveyed health facilities grouped by senatorial zone, category and geographical setting, Anambra State, Nigeria.

\begin{tabular}{l|lll|l}
\hline Health facilities & \multicolumn{3}{|c|}{ Senatorial zone } & Total \\
\cline { 2 - 4 } & $\begin{array}{l}\text { Anambra } \\
\text { north }\end{array}$ & $\begin{array}{l}\text { Anambra } \\
\text { south }\end{array}$ & $\begin{array}{l}\text { Anambra } \\
\text { central }\end{array}$ & \\
\hline By Category & & & & \\
\hline Tertiary & -- & 1 & -- & 1 \\
Secondary & 2 & 2 & 1 & 5 \\
Primary & 7 & 6 & 6 & 19 \\
Mission & 1 & 2 & 2 & 5 \\
Total & 10 & 11 & 9 & 30 \\
\hline By Geographical setting & & & \\
\hline Rural & 5 & 10 & 7 & 22 \\
Urban & 5 & 1 & 2 & 8 \\
Total & 10 & 11 & 9 & 30 \\
\hline
\end{tabular}

Table 2. Seven days per week operation and 24-hour service coverage in 30 facilities, Anambra State, Nigeria grouped by category of health facility.

\begin{tabular}{|c|c|c|}
\hline Category of Health Facility & $\begin{array}{l}\text { Number of } \\
\text { facilities } N=\mathbf{3 0}\end{array}$ & Percent \\
\hline \multicolumn{3}{|l|}{ Operational 7 days per week } \\
\hline $\begin{array}{l}\text { Tertiary }(n=1) \\
\text { Secondary }(n=5) \\
\text { Primary }(n=19) \\
\text { Mission }(n=5)\end{array}$ & $\begin{array}{l}1 \\
4 \\
18 \\
5\end{array}$ & $\begin{array}{l}100.0 \\
80.0 \\
94.7 \\
100.0\end{array}$ \\
\hline Total & 28 & 93.3 \\
\hline \multicolumn{3}{|c|}{ Availability of 24-hour service coverage } \\
\hline $\begin{array}{l}\text { Tertiary }(n=1) \\
\text { Secondary }(n=5) \\
\text { Primary }(n=19) \\
\text { Mission }(n=5)\end{array}$ & $\begin{array}{l}1 \\
4 \\
16 \\
5\end{array}$ & $\begin{array}{l}100.0 \\
80.0 \\
84.2 \\
100.0\end{array}$ \\
\hline Total & $\begin{array}{l}26 \\
86.7\end{array}$ & $\begin{array}{l}86.7 \\
--\end{array}$ \\
\hline
\end{tabular}

Table 3. Availability of Maternal Health Services in $\mathbf{3 0}$ health facilities, Anambra State.

\begin{tabular}{lll}
\hline Maternal Health Service & $\begin{array}{l}\text { Number of facilities } \\
\text { N=30 }\end{array}$ & Percent \\
\hline Ante-natal care & 29 & 96.7 \\
Delivery Services & 30 & 100.0 \\
Post-natal Care & 28 & 93.3 \\
Post-abortion care & 16 & 53.3 \\
Family Planning & 24 & 80.0 \\
\hline
\end{tabular}

health facilities) while 24 offered family planning services.

\section{Emergency obstetric care}

Table 4 shows the proportion of facilities that performed the signal functions for emergency obstetric care (EmOC) and on this basis were further categorised as basic or comprehensive EmOC facilities. 
Ifeadike et al. Research Journal of Women's Health 2016,

http://www.hoajonline.com/journals/pdf/2054-9865-3-2.pdf

doi: $10.7243 / 2054-9865-3-2$

Table 4. Signal functions and type of emergency obstetric care in 30 health facilities, Anambra State, Nigeria.

\begin{tabular}{lll}
\hline Signal function/type of EmOC & $\begin{array}{l}\text { Number of } \\
\text { facilities N=30 }\end{array}$ & Percent \\
\hline Signal function & & \\
\hline Parenteral antibiotics & 25 & 83.3 \\
Parenteral oxytocics & 25 & 83.3 \\
Parenteral anticonvulsants & 22 & 73.3 \\
Manual removal of placenta & 14 & 46.7 \\
Removal of retained products of & 21 & 70.0 \\
conception & & \\
Assisted vaginal delivery & 12 & 40.0 \\
Basic neonatal resuscitation & 21 & 70.0 \\
Caesarean Section & 9 & 30.0 \\
Blood transfusion & 9 & 30.0 \\
\hline Type of EmOC & & \\
\hline Basic EmOC & 1 & 3.3 \\
Comprehensive EmOC & 8 & 26.7 \\
Basic EmOC “minus 1 & 5 & 16.7 \\
Comprehensive EmOC “minus $1^{\text {’d }}$ & 1 & 3.3 \\
Not applicable & 15 & 50.0 \\
\hline
\end{tabular}

${ }^{\mathrm{a} A}$ basic Emergency obstetric care (EmOC) facility performs the following six signal functions: parenteral antibiotics; parenteral oxytocics; parenteral anticonvulsants; manual removal of placenta; removal of retained products of conception; assisted vaginal delivery;and basic neonatal resuscitation.

${ }^{\mathrm{b}} \mathrm{A}$ comprehensive EmOC facility performs all six signal functions of basic EmOC with Caesarean section and blood transfusion.

${ }^{\mathrm{c}} \mathrm{BasicEmOC}$ without manual removal of placenta, assisted vaginal delivery or basic neonatal resuscitation

${ }^{\mathrm{d} C}$ ComprehensiveEmOC without manual removal of placenta

eDoes not meet criteria for Basic EmOC "minus 1"

\section{Skilled birth attendants}

Table 5 presents the distribution of skilled birth attendants in the surveyed health facilities. A total of 1067 skilled birth attendants were in the 30 health facilities included in the study. The bulk of the health workers were found in the tertiary facility. Out of a total of 360 doctors working in the 30 health facilities 251 (69.7 percent) were in the tertiary facility; a similar picture was observed for the nurse-midwives.

\section{Use of partograph during labour}

The facilities were assessed for the frequency in the use of a partograph for monitoring labour. The partograph is a lowcost graphical tool that can be used in developing countries for monitoring labour where cardiotocographs are not available [17]. Seven health facilities always used a partograph; this included the federal government-owned tertiary centre, one general hospital, three primary facilities and two mission facilities. Ten health facilities sometimes used the partograph while 13 never used this tool (Table 5).

\section{Availability of HIV/AIDS and STI services}

The survey obtained information on the following services:
Table 5. Distribution of 1067 skilled birth attendants and frequency of the use of partograph for monitoring labour in 30 health facilities, Anambra State, Nigeria.

\begin{tabular}{lll}
\hline Variable & Number & Percent \\
\hline Category of skilled birth attendant & $\begin{array}{l}\text { Health workers } \\
(\mathrm{N}=1067)\end{array}$ & -- \\
Nurse-midwives (double qualified) & 613 & 57.5 \\
Medical doctors (non-obstetrician) & 332 & 31.1 \\
Registered midwives (single qualified) & 45 & 4.2 \\
Obstetricians & 28 & 2.6 \\
Registered nurses (single qualified) & 27 & 2.5 \\
Nurse/midwife community health & 22 & 2.1 \\
officers & & \\
Use of partograph & Facilities (N=30) & -- \\
Always used & 7 & 23.3 \\
Sometimes used & 10 & 33.3 \\
Never used & 13 & 43.4 \\
\hline
\end{tabular}

HIV/AIDS counselling/IEC, HIV/AIDS voluntary testing, HIV anti-retroviral treatment, counselling about other STIs/IEC, diagnosis of other STIs, and treatment of other STIs (Table 6). All services were available at the tertiary facility. One health facility did not provide HIV/AIDS counselling, information and education while 27 health facilities performed HIV testing. Seven health facilities provided antiretroviral treatment (the national teaching hospital, two general hospitals and four mission hospitals) while counselling, diagnosis and treatment for STIs were provided by 28,22 and 27 of the health facilities respectively.

Table 6. Availability of HIV/AIDS and STI services; treatment of non-communicable conditions of the reproductive tract and other reproductive health services in 30 health facilities, Anambra State, Nigeria.

\begin{tabular}{llc}
\hline Reproductive health service & $\begin{array}{l}\text { Number of facilities } \\
\text { N=30 }\end{array}$ & Percent \\
\hline HIV/AIDS and other STI services & & \\
HIV/AIDS counselling/IEC & 29 & 96.7 \\
HIV/AIDS voluntary testing & 27 & 90.0 \\
HIV anti-retroviral treatment & 7 & 23.3 \\
STI counselling/IEC & 28 & 93.3 \\
STI diagnosis & 22 & 73.3 \\
STI treatment & 27 & 90.0 \\
$\begin{array}{l}\text { Adolescent/youth-friendly health } \\
\text { service }\end{array}$ & 11 & 36.7 \\
\hline Treatment of non-communicable RT conditions/other RH \\
services & & \\
\hline $\begin{array}{l}\text { Treatment for RH Cancers } \\
\text { Fertility consultation }\end{array}$ & 6 & 20.0 \\
Counselling on menopause \& & 20 & 60.0 \\
andropause & & 66.7 \\
Counselling on sexual dysfunction & 21 & 70.0 \\
\hline
\end{tabular}


Provision of adolescent reproductive health services Only 11 health facilities in the study provided adolescent reproductive health care services (Table 6). These were the teaching hospital, one secondary facility five of the PHC facilities and four of the mission health facilities.

Treatment of non-communicable conditions of the reproductive tract and other reproductive health services Six health facilities provided treatment for reproductive tract cancers; these were the national teaching hospital, two general hospitals and three mission hospitals. Eighteen health facilities provided fertility consultations, 20 provided counselling on menopause and andropause, 10 of which were primary health facilities; and 21 provided counselling on sexuality dysfunction (Table 6).

\section{Equipment, supplies and infrastructure}

The provision of quality obstetric care and $\mathrm{EmOC}$ in particular is dependent on the availability of adequate equipment, supplies and infrastructure. However essential equipment, supplies and infrastructure were lacking in some facilities. For example, the manual vacuum aspirator used for treatment of first trimester miscarriages was available in good working condition in only 17 facilities. The non-pneumatic anti-shock garment (NASG), an effective first aid device that can be used in low-resource settings for management of obstetric haemorrhage [18] was found in 12 facilities. Magnesium sulphate was available in only seven health facilities while only 11 had piped running water (Table 7).

\section{Delivery records and caesarean section rate}

Out of a total of 7950 deliveries recorded in 2008 , there were 7475 normal deliveries ( 94 percent), 444 caesarean deliveries (5.6 percent) and 31 assisted vaginal deliveries ( 0.4 percent). The 19 primary health care facilities together accounted for only 10.2 percent of all the deliveries whereas the national teaching hospital recorded 2925 (36.8 percent) of the deliveries for that year (Table 8). Among the health facilities that recorded caesarean deliveries, the mission hospitals had the highest caesarean section rate of 13.2 percent compared to 2.7 percent for the national teaching hospital and 2.3 percent for the general hospitals. Overall, the caesarean section rate for the study was 6.2 percent (Table 9).

\section{Distribution of obstetric complications}

The distribution of cases and deaths from seven major obstetric complications is shown in Table 10. Overall, there were 354 cases and 39 deaths. Obstetric haemorrhage accounted for the majority of cases $(314 ; 88.7$ percent) followed by prolonged/ obstructed labour with 24 cases ( 6.8 percent). There were four cases of post-partum sepsis, six cases of complications from unsafe abortion, five cases of pre-eclampsia/eclampsia and one ectopic pregnancy. Fourteen mortalities occurred from obstetric haemorrhage giving rise to a case fatality rate of 4.5
Table 7. Distribution of selected equipment, supplies and infrastructure in $\mathbf{3 0}$ health facilities, Anambra State, Nigeria.

\begin{tabular}{lll}
\hline Equipment/Supplies/Infrastructure & $\begin{array}{l}\text { Number of } \\
\text { facilities N=30 }\end{array}$ & Percent \\
\hline \multicolumn{2}{l}{ Equipment in good working condition } & \\
\hline Sphygmomanometer & 28 & 93.3 \\
Manual vacuum aspirator & 17 & 56.7 \\
Sterilising equipment & 17 & 56.7 \\
Non-pneumatic anti-shock garment & 12 & 40.0 \\
Neonatal intubation set & 21 & 70.0 \\
Caesarean Section pack & 21 & 70.0 \\
Surgical gloves & 23 & 76.7 \\
\hline Supplies & & \\
\hline Parenteral antibiotics & 17 & 56.7 \\
Magnesium Sulphate & 7 & 23.3 \\
Parenteral oxytocics & 27 & 90.0 \\
Oxygen & 7 & 23.3 \\
Partograph & 16 & 53.3 \\
Ante-natal Risk Assessment Form & 10 & 33.3 \\
(ARAF) & & \\
\hline Infrastructure & 11 & 36.7 \\
\hline Piped running water & 26 & 86.7 \\
Working toilet & 20 & \\
\hline Electricity & 3 & \\
\hline National grid & & \\
Generating set & & \\
Solar panel & & \\
\hline
\end{tabular}

Table 8. Distribution of total deliveries recorded in 2008 in 30 health facilities, Anambra State, Nigeria, stratified by type of delivery and category of health facility.

\begin{tabular}{lll}
\hline Variable & $\begin{array}{l}\text { Number of } \\
\text { deliveries, N=7950 }\end{array}$ & Percent \\
\hline Type of delivery & & \\
\hline Normal delivery & 7475 & 94.0 \\
Caesarean delivery & 444 & 5.6 \\
Assisted vaginal delivery & 31 & 0.4 \\
\hline Category of health facility & & \\
\hline National teaching hospital $(\mathrm{N}=1)$ & 2925 & 36.8 \\
General hospitals (N=5) & 1740 & 21.9 \\
Primary health facilities (N=19) & 816 & 10.2 \\
Mission hospital $(\mathrm{N}=5)$ & 2469 & 31.1 \\
\hline
\end{tabular}

percent. Case fatality rates for prolonged/obstructed labour, sepsis and unsafe abortion were 58.3 percent, 75 percent and 83.3 percent respectively. Fifty-six percent of the maternal deaths occurred in the mission hospitals, 30.8 percent in the primary health care facilities while the national teaching hospital and the general hospitals accounted for 5.1 percent 
Ifeadike et al. Research Journal of Women's Health 2016,

Table 9. Caesarean section rates in surveyed health facilities that recorded caesarean deliveries in 2008, Anambra State, Nigeria stratified by category of health facility.

\begin{tabular}{llll}
\hline $\begin{array}{l}\text { Category of health } \\
\text { facility }^{\mathbf{a}}\end{array}$ & Deliveries & $\begin{array}{l}\text { Caesarean } \\
\text { sections }\end{array}$ & $\begin{array}{l}\text { Caesarean } \\
\text { section rate (\%) }\end{array}$ \\
\hline $\begin{array}{l}\text { National teaching } \\
\text { hospital }\end{array}$ & 2925 & 79 & 2.7 \\
General hospitals & 1740 & 40 & 2.3 \\
Mission hospital & 2469 & 325 & 13.2 \\
Total & 7134 & 444 & 6.2 \\
\hline
\end{tabular}

${ }^{a}$ No caesarean delivery was recorded in any of the primary health facilities

Table 10. Distribution of major obstetric complications and deaths recorded in 2008 in 30 health facilities, Anambra State, Nigeria.

\begin{tabular}{lllll}
\hline $\begin{array}{l}\text { Obstetric } \\
\text { complications }\end{array}$ & $\begin{array}{l}\text { Cases, N=354 } \\
\text { Number Percent }\end{array}$ & $\begin{array}{l}\text { Maternal } \\
\text { deaths } \\
\mathbf{N = 3 9}\end{array}$ & $\begin{array}{l}\text { Case fatality } \\
\text { rate (\%) }\end{array}$ \\
\hline $\begin{array}{l}\text { Obstetric } \\
\text { haemorrhage }\end{array}$ & 314 & 88.7 & 14 & 4.5 \\
$\begin{array}{l}\text { Prolonged/ } \\
\text { obstructed labour }\end{array}$ & 24 & 6.8 & 14 & 58.3 \\
$\begin{array}{l}\text { Post partum sepsis } \\
\text { Unsafe abortion }\end{array}$ & 4 & 1.1 & 3 & 75.0 \\
$\begin{array}{l}\text { Pre-eclampsia/ } \\
\text { eclampsia }\end{array}$ & 5 & 1.7 & 5 & 83.3 \\
$\begin{array}{l}\text { Ectopic } \\
\text { Pregnancy }\end{array}$ & 1 & 0.3 & 1.4 & 40.0 \\
Ruptured uterus & 0 & 0.0 & 0 & 100.0 \\
\hline
\end{tabular}

and 7.7 percent of the maternal deaths respectively.

\section{Discussion}

Health data is critical to improving the health of populations as it plays a vital role in identifying their needs and determining solutions to their health problems. This studytook a close look at reproductive health services in the Anambra State health system. It was however limited by incompleteness of information obtained and in some cases a total lack of records regarding certain aspects of the study.

Access to reproductive health services particularly maternal and child health services is fairly good in Anambra State. Many of the health facilities provided 24-hour services and were open seven days a week. Although there are many factors that contribute to maternal mortality, access to 24-hour emergency obstetric care, along side availability of skilled attendance at delivery, is one the most effective ways of preventing maternal death [19]. Nnebue et al., [20] in their study on the adequacy of resources for maternal health services in primary health care facilities in Nnewi, Nigeria found that a lack of residential accommodation for health facility staff and security personnel prevented the facilities from providing 24-hour service [20].

Maternal mortality remains a serious problem in Nigeria. Although some progress was made on the fifth millennium development goal -reduce the maternal mortality ratio (MMR) by three quarters between 1990 and 2015-Nigeria is unlikely to achieve it. The survey showed 11 percent maternal mortality from seven major obstetric complications but this did not include mortality data from traditional birth attendants, traditional healers, maternity homes and other sources.

Majority of the secondary and primary health care facilities failed to meet the standard for Basic EmOC which has serious implications for their ability to manage emergency obstetric and newborn conditions. Assisted vaginal delivery was generally lacking as just 12 facilities offered the service. Furthermore only 31 out the 7950 deliveries (0.4\%) recorded in 2008 where assisted vaginal deliveries which may reflect a lack of skills for such procedures rather than the occurrence of few indications or provider bias against assisted vaginal delivery [17]. Adequate training of skilled birth attendants could mitigate this and will prevent any unnecessary caesarean operations for prolonged second stage [17]. Unfortunately, global trends over the past two decades show declining rates of assisted vaginal delivery while caesarean section rates have been on the increase. Both types of instrumental vaginal delivery (vacuum extraction or forceps) have clear indications for use and can potentially not only reduce the risks associated with caesarean sections but also lower the cost of obstetric care [21].

Skilled attendance means that a pregnant woman and her infant receive adequate care during pregnancy, labour, delivery, and the postpartum and immediate newborn periods, whether she gives birth at home, in a health centre, or hospital. Importantly, the attendant must have the necessary skills and must be supported by an enabling environment at various levels of the health system [19]. The World Health Organisation defines a skilled birth attendant as an accredited health professional-such as a midwife, doctor or nurse who has been educated and trained to the level of proficiency in the skills needed to manage uncomplicated pregnancies, childbirth and the immediate postnatal period, and in the identification, management and referral of complications in women and newborns [22]. Non-nurse/midwife community health officers, community health extension workers, auxiliary nurses and traditional birth attendants are not regarded as skilled birth attendants. Skilled health workers were inadequate among the health facilities in this study, similar to what was observed by Wilunda et al., in the Karamoja region, Uganda [23]. There was also an inequitable distribution of the health care workers with the bulk of the doctors and double qualified nurse-midwives found in the tertiary facility $(69.7$ percent and 62.2 percent respectively).

Aside from maternal health services, the most commonly provided reproductive health services were HIV and STI 
care possibly because a large share of the funding for these conditions is donor-driven $[\mathbf{2 4 , 2 5}]$. This may have given rise to the so-called 'dependency syndrome' [26] resulting in less political will and funding from the State government to other areas of reproductive health such as adolescent sexual and reproductive health, reproductive cancers e.t.c. Few health facilities in the study offered adolescent reproductive health services. Due to the unique reproductive and sexual needs of adolescents, access to youth friendly services is paramount to ensure their sexual and reproductive health and wellbeing [27]. Denno et al., [27] found positive associations between strategies that combined training of health workers, improvements in adolescent-friendly facilities, and broad information dissemination and outcomes such as uptake of SRHS or sexual and reproductive health commodities and sexual and reproductive health biologic outcomes. It is hoped that the information provided here would stimulate improvements or changes in reproductive health policy, financing, implementation, and monitoring and evaluation of health facilities in the State and by extension the Anambra State health care delivery system thereby completing a significant step towards improving sexual and reproductive health in Nigeria.

\section{Conclusion}

This study has served to provide baseline information for the implementation of reproductive health care in Anambra State. Information has been presented on the magnitude of the problem including the health system functions and performance; the quality of available services including essential obstetric and newborn care, prevention of mother to child transmission of HIV, adolescent health e.t.c. Equipment such as the manual vacuum aspirator and the non-pneumatic antishock garment were unavailable in several facilities as well as supplies such as magnesium sulphate, oxygen, partographs and piped running water.

We recommend regular monitoring and supervisory visits and an annual accreditation process that will determine deficiencies, constraints and challenges to providing reproductive health in health facilities in the State, which will help improve service delivery. Further studies are needed in this area to help a better understanding of the availability and utilisation of reproductive health services.

\section{Competing interests}

The authors declare that they have no competing interests.

Authors' contributions

\begin{tabular}{|l|c|c|c|c|c|c|}
\hline Authors' contributions & COI & NNE & GAN & OFE & UMU & CCO \\
\hline Research concept and design & $\checkmark$ & $\checkmark$ & -- & -- & -- & -- \\
\hline $\begin{array}{l}\text { Collection and/or assembly of } \\
\text { data }\end{array}$ & $\checkmark$ & $\checkmark$ & -- & -- & -- & -- \\
\hline Data analysis and interpretation & $\checkmark$ & $\checkmark$ & $\checkmark$ & $\checkmark$ & $\checkmark$ & $\checkmark$ \\
\hline Writing the article & $\checkmark$ & $\checkmark$ & $\checkmark$ & -- & -- & $\checkmark$ \\
\hline Critical revision of the article & $\checkmark$ & $\checkmark$ & $\checkmark$ & $\checkmark$ & $\checkmark$ & $\checkmark$ \\
\hline Final approval of article & $\checkmark$ & $\checkmark$ & $\checkmark$ & $\checkmark$ & $\checkmark$ & $\checkmark$ \\
\hline
\end{tabular}

\section{Acknowledgement}

We acknowledge the staff of Community medicine Department for their efforts in the preparation of this study.

\section{Publication history}

Editor: Erich Cosmi, University of Padua, Italy.

Received: 23-Sep-2016 Final Revised: 21-Oct-2016

Accepted: 01-Nov-2016 Published: 11-Nov-2016

\section{References}

1. UNFPA, "Reproductive health: An evolving concept and expanding agenda. Sexual and Reproductive Health for All. Reducing poverty, advancing development and protecting human rights. 2010; 13-17. I Pdf

2. Oyediran KO, Makinde OA and Mullen S. Monitoring and evaluation of sexual and reproductive health programmes. In: Confronting the challenge of reproductive health in Africa: A textbook for students and development practitioners. Okonfua F. (ed.) Women's Health and Action Resource Centre. Florida: Brown Walker Press. 2014. | Pdf

3. World Health Organisation. DALYs and reproductive health. Report of an informal consultation 27-28 April 1998; WHO/RHT/98.28. Division of Reproductive Health, World Health Organisation, 1999]. I Pdf

4. National Population Commission (NPC) Nigeria, ICF Macro. Nigeria Demographic and Health Survey 2013. Abuja, Nigeria: National Population Commission and ICF Macro. 2014; 140-279. | Pdf

5. Daru P.H. Health Bill and MDGS 4, 5 \& 6, Tropical. Journal of Obstetrics and Gynaecology. 2013; 30. I Website

6. Ogunjimi L.O, Ibe R.T and Ikorok M.M. Curbing maternal and child mortality: The Nigerian experience. International Journal of Nursing Midwifery. 2012; 3:33-39. I Pdf

7. Ujah IA, Aisien OA, Mutihir JT, Vanderjagt DJ, Glew RH and Uguru VE. Factors contributing to maternal mortality in north-central Nigeria: a seventeen-year review. Afr J Reprod Health. 2005; 9:27-40. | Article | PubMed

8. Igwegbe AO, Eleje GU, Ugboaja JO and Ofiaeli RO. Improving maternal mortality at a university teaching hospital in Nnewi, Nigeria. Int J Gynaecol Obstet. 2012; 116:197-200. | Article | PubMed

9. Omo-Aghoja LO, Aisien OA, Akuse J.T and Bergstrom FE. Maternal mortality and emergency obstetric care in Benin City, South-south Nigeria. J Clin Med Res. 2010; 2:55-60. I Pdf

10. RAISE, Fact sheet. Emergency obstetric care. 2007. I Pdf

11. UNFPA. Setting standards for emergency obstetric and newborn care. 2014. I Website

12. World Health Organisation, UNFPA, UNICEF, AMDD. Monitoring emergency obstetric care. A handbook. [E-book]. World Health Organisation, Geneva, Switzerland. 2009. I Website

13. National Population Commission. Population distribution by sex, state, LGAs and senatorial district: 2006 census priority tables. Abuja, Nigeria. 2010; 3:49-51. | Website

14. National Bureau of Statistics (NBS). Statistical report on women and men in Nigeria, 2013. Abuja, Nigeria. National Bureau of Statistics. 2014: 1-4. I Pdf

15. National Bureau of Statistics (NBS), United Nations Children's Fund (UNICEF). United Nations Population Fund (UNFPA). Nigeria: Multiple Indicator Cluster Survey 2011, Main report, Abuja. Nigeria: National Bureau of Statistics. 2013; 90-114. I Pdf

16. Anambra State Ministry of Health. Anambra State Government Strategic Health Development Plan. Anambra State, Nigeria, Ministry of Health. 2010: 13-21. | Pdf

17. Ziraba AK, Mills S, Madise N, Saliku T and Fotso JC. The state of emergency obstetric care services in Nairobi informal settlements and environs: results from a maternity health facility survey. BMC Health Serv Res. 2009; 9:46. | Article | PubMed Abstract | PubMed FullText

18. Miller $\mathrm{S}$ and Belizan JM. A promising device to save maternal lives associated with obstetric hemorrhage: the non-pneumatic anti-shock garment (NASG). Reprod Health. 2015; 12:26. I Article I PubMed 
Ifeadike et al. Research Journal of Women's Health 2016,

Abstract | PubMed FullText

19. World Bank. Maternal mortality fact sheet. Public health at a glance. 2006. | Website

20. Nnebue C.C, Ebenebe U.E, Adogu P.O.U, Adinma E.D, Ifeadike C.O and Nwabueze A.S. Adequacy of resources for provision of maternal health care services at primary health care level in Nnewi, Nigeria. Nigerian Medical Journal. 2014; 55:235-241. | Article

21. Bailey PE. The disappearing art of instrumental delivery: time to reverse the trend. Int J Gynaecol Obstet. 2005; 91:89-96. | Article | PubMed

22. Making pregnancy safer-The critical role of the skilled attendant. A joint statement by WHO, ICM and FIGO. Geneva, World Health Organisation). I Website

23. Wilunda C, Oyerinde K, Putoto G, Lochoro P, Dall'Oglio G, Manenti F, Segafredo G, Atzori A, Criel B, Panza A and Quaglio G. Availability, utilisation and quality of maternal and neonatal health care services in Karamoja region, Uganda: a health facility-based survey. Reprod Health. 2015; 12:30. | Article | PubMed Abstract | PubMed FullText

24. The United States President's Emergency Plan for AIDS Relief (PEPFAR). Country operational plan narratives: Nigeria. 2009. | Website

25. Ndoh KI. Funding sustainability for HIV/AIDS prevention, treatment and care in Nigeria. [Thesis] University of Washington. 2013. I Website

26. Akinola AO. Foreign aids in Africa: From realities to contradictions. Global Advanced Research Journal of Social Science. 2012; 1:12-17.

27. Denno DM, Hoopes AJ and Chandra-Mouli V. Effective strategies to provide adolescent sexual and reproductive health services and to increase demand and community support. J Adolesc Health. 2015; 56:S22-41. | Article | PubMed

\section{Citation:}

Ifeadike CO, Ezeama NN, Nnaji GA, Emelumadu OF, Ugwoke U and Ofoegbu CC. An assessment of reproductive health services in selected health facilities, Anambra State, Nigeria. Res J Womens Health. 2016; 3:2. http://dx.doi.org/10.7243/2054-9865-3-2 